\title{
Symptomatic Scaphotrapeziotrapezoid Carpal Coalition: The Natural History and a Surgical Option for Treatment
}

\author{
M. Sajjad Athar*, George Aerialis, Neil Ashwood, Gregory Bain \\ Queens Hospital, Burton-upon-Trent, UK \\ Email: ^msathar@hotmail.com
}

How to cite this paper: Athar, M.S., Aerialis, G., Ashwood, N. and Bain, G. (2017) Symptomatic Scaphotrapeziotrapezoid Carpal Coalition: The Natural History and a Surgical Option for Treatment. Open Journal of Orthopedics, 7, 127-139.

https://doi.org/10.4236/ojo.2017.75015

Received: April 12, 2017

Accepted: May 23, 2017

Published: May 26, 2017

Copyright (c) 2017 by authors and Scientific Research Publishing Inc. This work is licensed under the Creative Commons Attribution International License (CC BY 4.0).

http://creativecommons.org/licenses/by/4.0/

\begin{abstract}
Carpal coalitions are uncommon and are frequently asymptomatic. $15 \mathrm{~Pa}-$ tients with persistent symptomatic scaphotrapeziotrapezoid (STT) carpal coalitions unresponsive to six months of conservative treatment with no history of trauma went for further investigations. CT scans and bone scans revealed that coalition was the only abnormality to account for the patient's ongoing problems. The senior authors explored the carpal coalition surgically excising the affected region and interposing capsular fibrous tissue. Histologically partial bony and cartilaginous bridging was evident with no features of degenerative arthritis being noted. Good or excellent subjective results were achieved in all patients at final review an average of 2.7 (1.0 - 4.2) years after surgery. All patients described significant reduction in visual analogue pain scores from an average of 71.5 to 18.4 points. The Green and O'Brien wrist scores improved from a mean of 58.2 to 94.2 , with all patients returning to work with improved function. Normally carpal coalition is treated with arthrodesis or excision of part of the carpus. A further treatment option is outlined here with recreation of the joint space in symptomatic, isolated, nonsyndromic scaphotrapezio-trapezoidal coalition.
\end{abstract}

\section{Keywords}

Carpal Coalition, Hand, Symptomatic STT Coalition, Capsular Interposition

\section{Introduction}

Carpal fusion, synostosis or coalition, as it is variously called, is often diagnosed as an incidental finding on radiographs performed for wrist trauma.

Previous authors have suggested that carpal coalitions are asymptomatic [1] and develop after failure of segmentation of the cartilaginous precursor of the 
carpal bones. There is now substantial support in the literature for non-syndromic isolated scaphotrapeziotrapezoid carpal coalitions going onto causing patients persistent pain, loss of motion and function in the wrist [2]-[7]. Others have generally treated such problems that fail to respond to conservative management with arthrodesis to augment the fusion [8] [9] or symptomatically treat any fracture through a coalition [4] [5]. Five bony synostoses were taken down in this series and capsular tissue was interposed to improve patient's symptoms with good results. The authors recommend this as another option for treating this rare but disabling condition.

\section{Materials and Methods}

We had five cases with an average age of $34.2(19-43)$ years at the time of surgery presented with persistent wrist pain with no specific history of trauma to the hand. There were three men and two females and all were in full time employment with two working in factories on a production line and three in construction. In keeping with presentations previously documented in the literature three of these cases had pain brought on by use, especially during employment with symptoms settling after cessation of these activities [10] [11].

The three patients with activity related pain all worked in factories and had been symptomatic for an average of seven (five, seven, nine) months. There had been no previous injury to the wrist. All three were referred to the senior authors by the patient's local medical provider with a dorsal wrist ganglion rather than because of wrist pain. The patient was subsequently noted to also have reproducible pain and a radiograph obtained that indicated the possibility of carpal coalition of the STT joint.

Two other patients presented with trauma but to other parts of the limb and were found to have a carpal coalition at the same time that subsequently remained symptomatic for six months before the patient's requested further treatment. This is in keeping with previous reports, for example, Ingram et al. in 1997, reported an STT coalition as an incidental finding whilst investigating a fifth metacarpal fracture in a young male.

One of the first patients treated in this series illustrates this presentation. A thirty four year old lady presented with a sore left forearm having been kicked in the forearm three weeks earlier by a horse. There was specific injury to that thumb but tenderness over the flexor pollicis brevis tendon was noted on examination. Plain radiographs showed what appeared to be a cystic connection between the scaphoid and trapezium (Figure 1). Initial treatment with wrist splints was advised but the patient continued to have ongoing pain in the left wrist. CT scan indicated bony contact between the scaphoid and trapezium (Figure 2). This was confirmed at the time of surgery with the two bones appearing to be contiguous (Figure 3) this area was explored given the cystic appearance on the radiograph. Histological examination of the specimen revealed a partial bony linkage with thinned articular surfaces. No degenerative fibrillation, myxoid degeneration or osteophyte formation was noted. The appearances were 


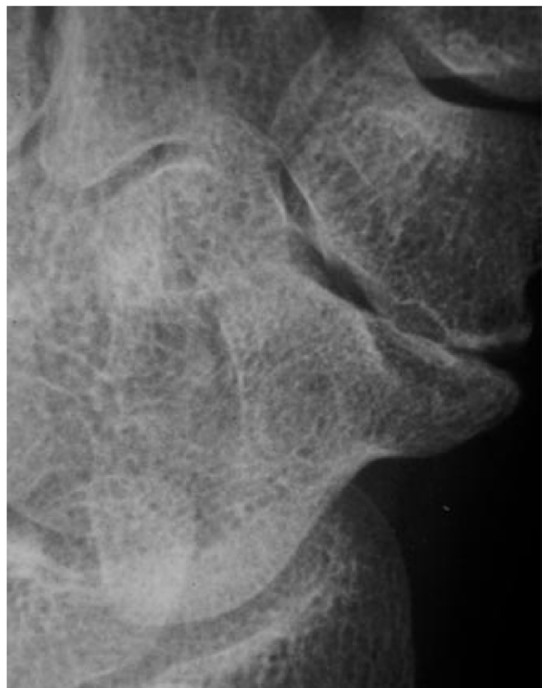

Figure 1. Thirty four years old who presented following forearm trauma.
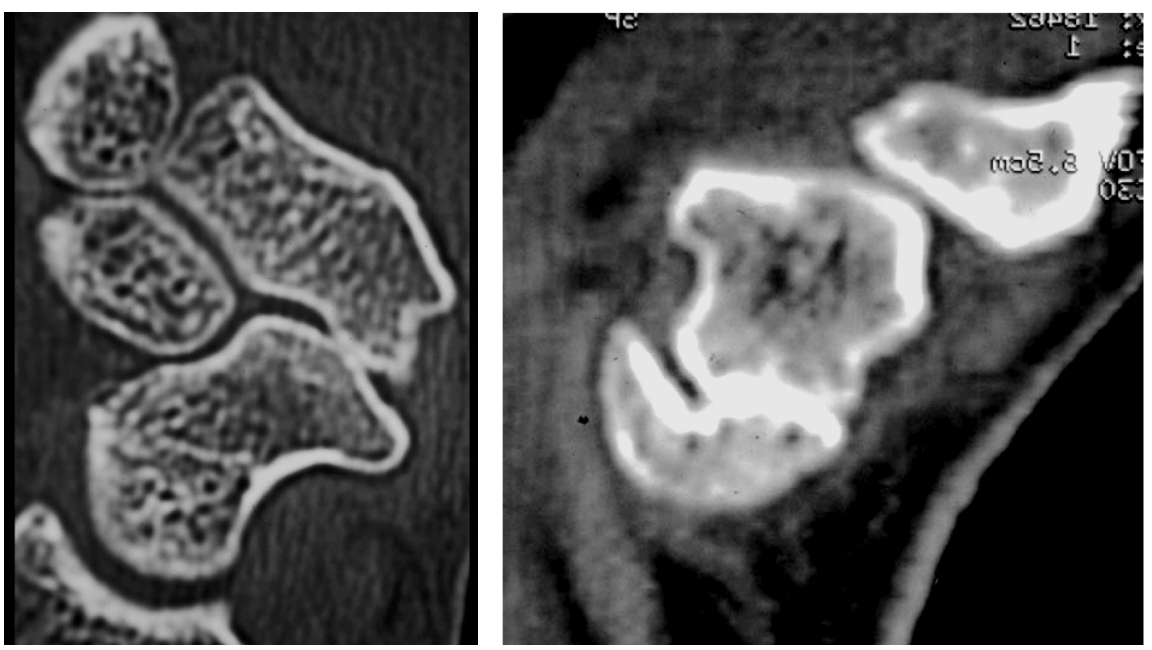

Figure 2. CT scan demonstrated cortical contact at the site of the scaphoid-trapezium articulation.

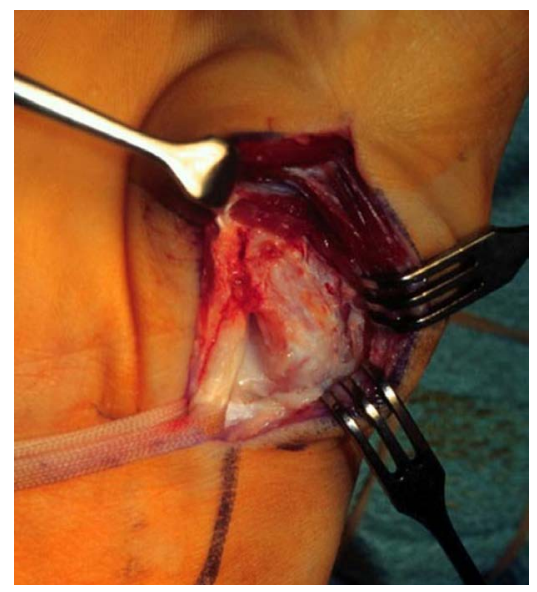

Figure 3. Trapezium and scaphoid in continuity at time of surgery. 
thought to be consistent with the proximal osseous bridge with distal notching described by Minaar in 1952 who published a classification of lunate-triquetral coalition from a series of 12 cases based on the degree of fusion and associated anomalies rather than osteoarthritic changes secondary to trauma.

The excised area was replaced at the time of surgery with capsule from the wrist joint to create an interposition arthroplasty (Figure 4). The surgical technique recommended by the authors is outlined later.

None of the patients with STT coalitions were pursuing claims against their employers or in relation to any injury. Symptoms occurred in the dominant limb and the pain was localised to the radial side of the wrist and base of the thumb for an average of 7.5 (6 to 9) months prior to patient's requesting further investigation and treatment. The persistent pain, swelling, restriction in motion plus loss of grip and pinch strength led the patients to seek a therapeutic intervention.

Assessment included clinical examination for local tenderness over the STT joint and stability. Range of motion of the wrist and grip strength was measured by a research nurse using a goniometer and dynamometer respectively prior to surgery and at follow up. Key, chuck and tip pinch strengths were assessed using a Jamar pinch gauge. Visual analogue scales were used to record pain and satisfaction levels. Any limitations to the activities of daily living were noted, enabling the Green and O'Brien wrist scores to be monitored. All information was recorded on a computer data base prospectively. The contralateral normal side was evaluated for comparison.

Radiographs (Figure 5) showed joint narrowing and suggest what appears to be a bony connection between the scaphoid, trapezium and trapezoid at the site

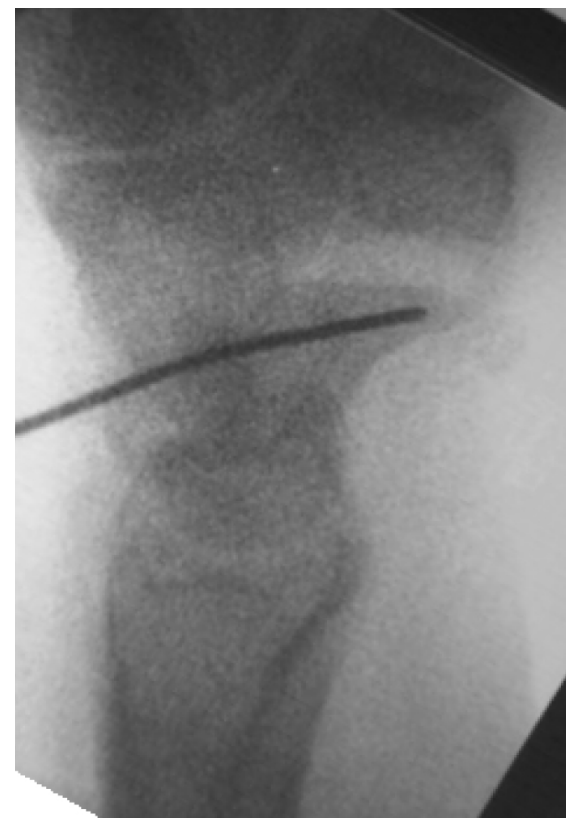

Figure 4. Post operative radiograph showing the interposition arthroplasty created at the time of surgery. 


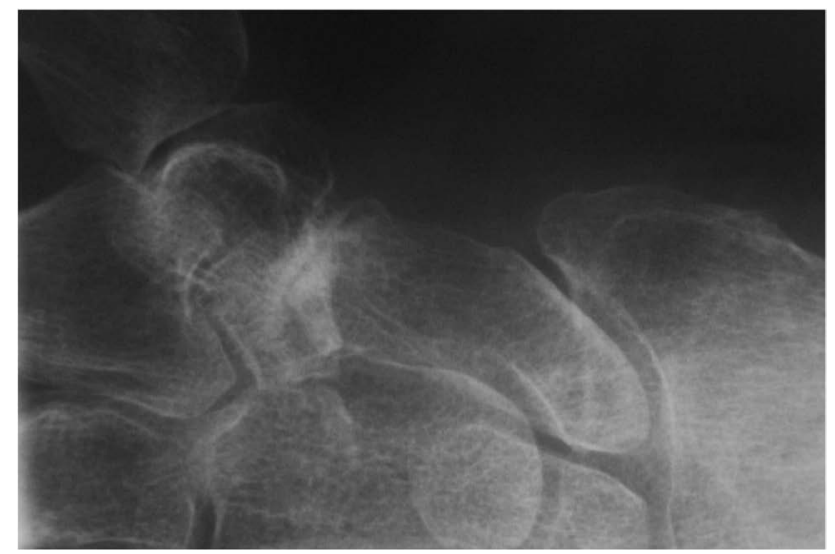

Figure 5. Radiograph showing the features of STT coalition.

of the STT joint. Multiple projections [12] [13] are often required and care must be taken not to confuse true congenital coalitions with fusions secondary to acquired disease [14].

CT scans (Figure 6) performed in all patients additionally showed the close apposition between the scaphoid, trapezium plus trapezoid and demonstrated the lack of a clear synovial joint articulation. All patients in this series also had a preoperative technetium 99 radionuclide bone scan (Figure 7) which typically show increased uptake in the triscaphe area but not specifically at the site of the articulations between these bones. This investigation helped to confirm that the patient's symptoms were not related to arthritic changes or to pathology arising from elsewhere within the wrist.

Carpal coalition diagnosis is difficult and while suggested by the history, examination and imaging should be confirmed by histological assessment and the findings at surgical exploration.

\section{Surgical Technique}

The scaphotrapeziotrapezoid joints can be approached in a number of ways depending on the exact location of the coalition. In this series the bony linkages were predominantly between scaphoid and trapezium, being approached through a curved incision on the dorsoradial aspect of the thumb metacarpal and wrist similar to that described by Wagner, 1950 [15]. To expose the trapezium and scaphoid the tendons of extensor pollicis brevis and abductor pollicis longus can be retracted to one side. This can be facilitated by partially stripping the soft tissue from the proximal end of the metacarpal. Alternatively if the coalition lies posteriorly a dorsal approach over the STT area is made via a longitudinal or transverse incision. The branches of the superficial radial nerve and veins are retracted. The extensor retinaculum is opened in line with the tendon of the extensor pollicis longus. The STT joint is exposed by opening the wrist capsule between the first and second dorsal tendon compartments. Care should be taken when using both approaches not to damage the radial artery or its branches. 


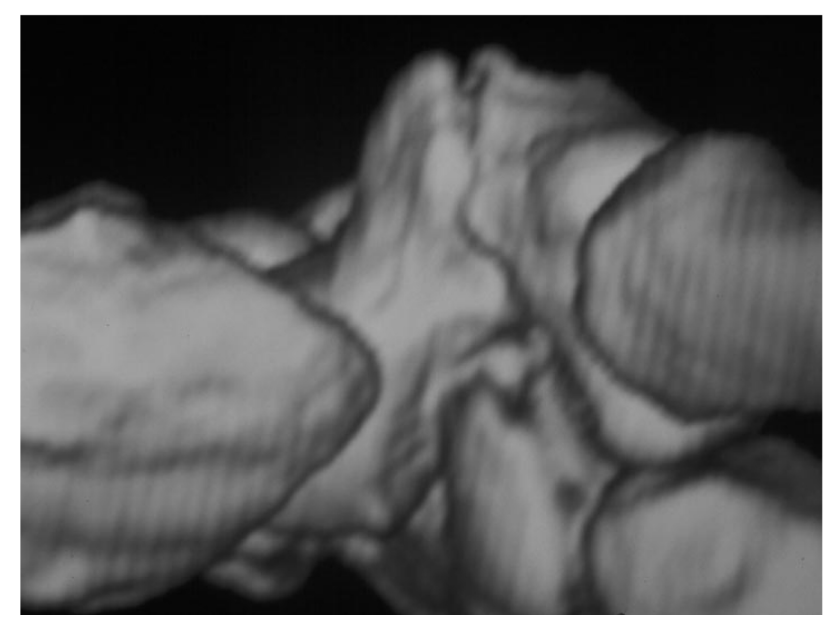

Figure 6. CT Scan-STT coalition.

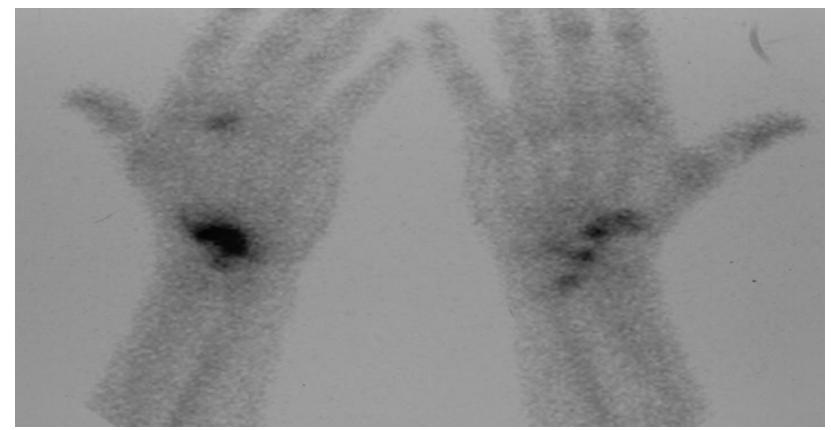

Figure 7. Bone scan indicating radial based wrist pathology.

The coalition can then be approached directly (Figure 8) and the affected area excised to reveal the remaining portion of normal joint (Figure 9). Fluoroscopic examination is used to confirm the site of the coalition prior to excision. At operation, the excised STT synchondrosis was sent for histological assessment and resection of the distal $3-4 \mathrm{~mm}$ of the scaphoid was performed. The joint capsule was used as an interposition graft in the space that remained.

Wounds were closed with re-absorbable suture and the wrist was immobilised in plaster for six weeks and then a removable splint used for the following six weeks.

Following surgery gentle mobilisation was permitted within the patient's pain tolerance. Return to light duties was recommended from eight weeks and heavy manual labour was avoided for a minimum of three months.

\section{Results}

Prior to surgery four patients could be categorised as having fair wrist function and one poor based on the modified Green and O'Brien, 1978 [16] wrist scores. All patients (Table 1) had a minimum follow up of one year with an average of 31 (12 - 50) months. The results are summarized in Table 2. Pain and functional discomfort were alleviated in all cases. This is reflected by the improvement in the average wrist score following surgery which had increased by 36 points at the 


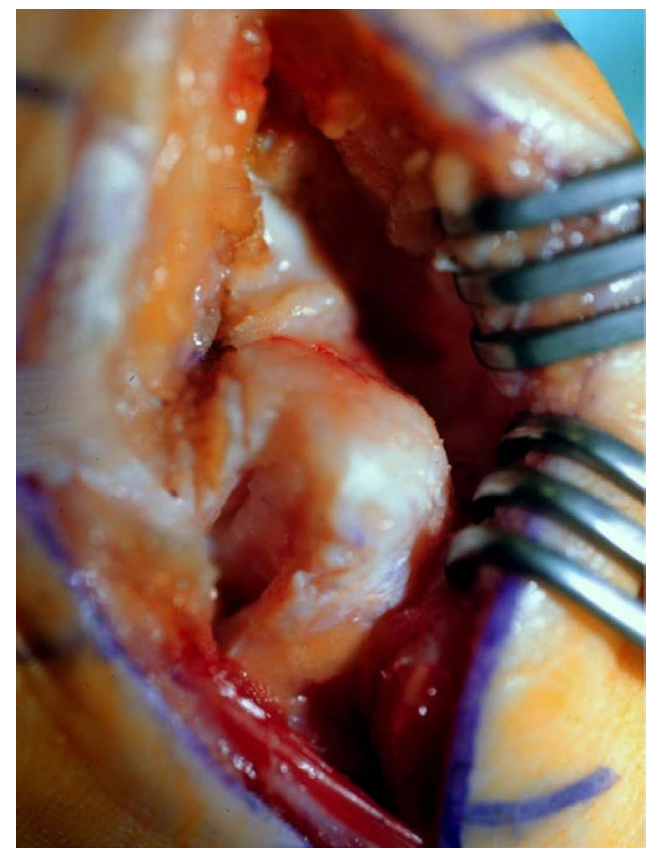

Figure 8. Appearances of coalition following approach.

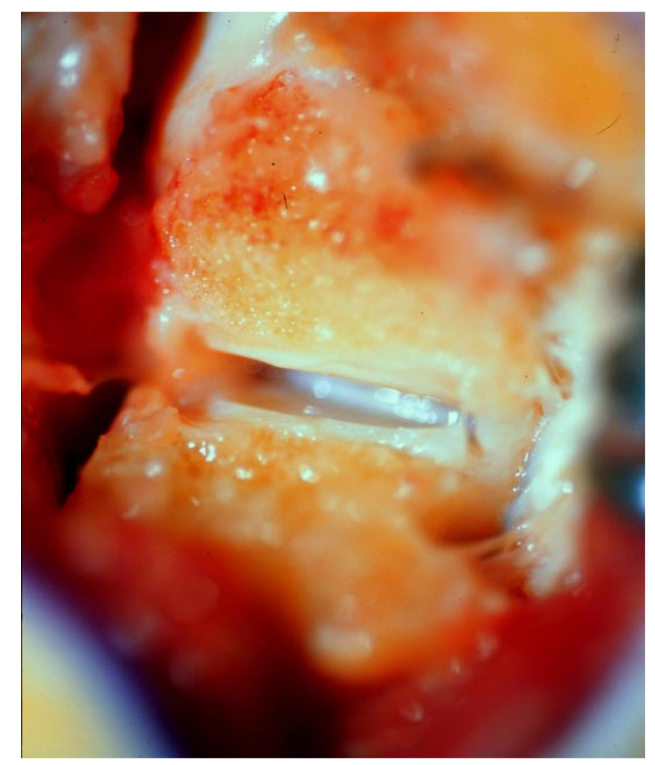

Figure 9. Appearances following excision of coalition.

one year review, with patient's now fitting into good (2) or excellent (3) categories. The patients all returned to work by three months without the use of any external splints. The wrist scores were maintained in the two patients reviewed at least three years post operation.

Mild pain occurred with strenuous repetitive activities in the remaining individuals, but did not interfere with work or recreational pursuits. The results had not deteriorated by the last review and are reflected by the visual analogue pain score remaining low at an average score of $11(0-25)$. 
Table 1. Demographic and presentation of patients.

\begin{tabular}{|c|c|c|c|c|c|}
\hline age & sex & $\begin{array}{l}\text { Righ } \\
\text { t/left }\end{array}$ & presentation & diagnosed & Follow up \\
\hline 34 & $\mathrm{~F}$ & $\mathrm{~L}$ & $\begin{array}{l}\text { Wrist pain after being } \\
\text { kicked by horse and } \\
\text { weak grip strength }\end{array}$ & $\begin{array}{l}\text { CT done one year after } \\
\text { injury \& confirmed at } \\
\text { surgery }\end{array}$ & $\begin{array}{l}\text { Returned to sports } \\
\text { at one year }\end{array}$ \\
\hline 19 & M & $\mathrm{L}$ & $\begin{array}{l}\text { Thumb pain after kick in } \\
\text { forearm }\end{array}$ & $\begin{array}{l}\text { CT one year later \& } \\
\text { confirmed at surgery }\end{array}$ & $\begin{array}{l}\text { Returned to } \\
\text { contact sports } \\
\text { at one year }\end{array}$ \\
\hline 43 & $\mathrm{~F}$ & $\mathrm{~L}$ & $\begin{array}{l}\text { Fall at work, persistent } \\
\text { pain \& swelling }\end{array}$ & $\begin{array}{c}\text { CT showed } \\
\text { synchondrosis \& } \\
\text { confirmed at surgery }\end{array}$ & return to work \\
\hline 39 & M & $\mathrm{L}$ & $\begin{array}{l}\text { Fall on outstretched } \\
\text { hand, pain \& swelling }\end{array}$ & $\begin{array}{c}\text { CT showed bony } \\
\text { coalition \& confirmed } \\
\text { at surgery }\end{array}$ & Returned to work \\
\hline 36 & M & $\mathrm{R}$ & $\begin{array}{l}\text { After colliding with } \\
\text { other person pain and } \\
\text { weakness }\end{array}$ & $\begin{array}{l}\text { CT showed coalition \& } \\
\text { confirmed at surgery }\end{array}$ & Returned to work \\
\hline
\end{tabular}

Table 2. Summary of results before and after surgery for carpal coalition.

\begin{tabular}{|c|c|c|}
\hline & Preoperative score & $\begin{array}{c}\text { Most recent postoperative } \\
\text { score }\end{array}$ \\
\hline Pain (Visual analogue score) & $90(75-95)$ & $11(0-25)$ \\
\hline Normal activities score & $3(2-6)$ & $11(9-12)$ \\
\hline Flexion (degrees) & $50(40-65)$ & $65(55-70)$ \\
\hline Extension (degrees) & $45(36-54)$ & $60(55-70)$ \\
\hline Radial deviation (degrees) & $10(6-14)$ & $15(12-25)$ \\
\hline Ulnar deviation (degrees) & $18(10-30)$ & $25(18-32)$ \\
\hline $\begin{array}{l}\text { Key pinch strength } \\
\text { (kilograms) }\end{array}$ & $4(3-9)$ & $11(7-14)$ \\
\hline Grip strength (kilograms) & $18(14-31)$ & $35(24-49)$ \\
\hline $\begin{array}{c}\text { Green }+ \text { O'Brien Scores } \\
\text { (points) }\end{array}$ & $58(45-75)$ & $94(90-95)$ \\
\hline
\end{tabular}

All patients were satisfied with the outcome and would have repeated the surgery. Two patients', although content with the improvement of function, pain levels and grip strength were not completely satisfied with the level of wrist motion compared to the other arm.

Grip strength averages improved from 18 to 35 kilograms, which was similar to the opposite limb. Key pinch strengths were $40 \%$ preoperatively and $85 \%$ following surgery compared to the contralateral side. Radioulnar deviation improved from a mean of $25\left(16^{\circ}-40^{\circ}\right)$ preoperatively to an arc of $40\left(30^{\circ}-55^{\circ}\right)$ after surgery, which was still considerably less than the unaffected side $52\left(40^{\circ}\right.$ $\left.65^{\circ}\right)$. The average flexion-extension arc also improved from $95\left(85^{\circ}-135^{\circ}\right)$ to $125\left(110^{\circ}-135^{\circ}\right)$, achieving a level that was comparable to the other side 130 $\left(115^{\circ}-150^{\circ}\right)$. 
No significant deterioration in carpal angles was noted before and after surgery. The scapholunate angle was $35\left(20^{\circ}-50^{\circ}\right)$ preoperatively and $40\left(25^{\circ}-55^{\circ}\right)$ postoperatively. Also the capitolunate angle remained less than $15^{\circ}$ before (average $10^{\circ}$ ) and after (average $12^{\circ}$ ) operation (Figure 10).

\section{Discussion}

Carpal coalitions are most commonly incidental findings. Unlike tarsal coalitions they are usually asymptomatic. When symptomatic they are one of the differential diagnoses included in wrist pain.

The formation of the carpal bones begins with the cavitation of a common cartilaginous precursor into the individual bones during the first trimester. Failure of segmentation results in a synostosis (union of bones via bony bridging) or synchondrosis [17] [18] [19] [20] (union of bones by means of cartilage) or syndesmosis (fibrous union) which only becomes evident as the carpus ossifies.

Carpal coalition was first described by Sandifort in 1779 and the first clinical case report of carpal coalition was by Corson in 1908 [18].

The incidence of carpal coalition is reported to be $0.1 \%$ in Caucasians, but $9 \%$ of the population in some West African tribes [1] [15] [21]. Delaney et al. described a series of 36 carpal coalitions in 24 individuals and reported $61.5 \%$ to be bilateral [1] [21]. The male to female ratio was approximately 2:1 [21] with a varying racial distribution. This wide variation in incidence geographically indicates the importance of genetic factors [20]. 32 were lunotriquetral coalitions, 2

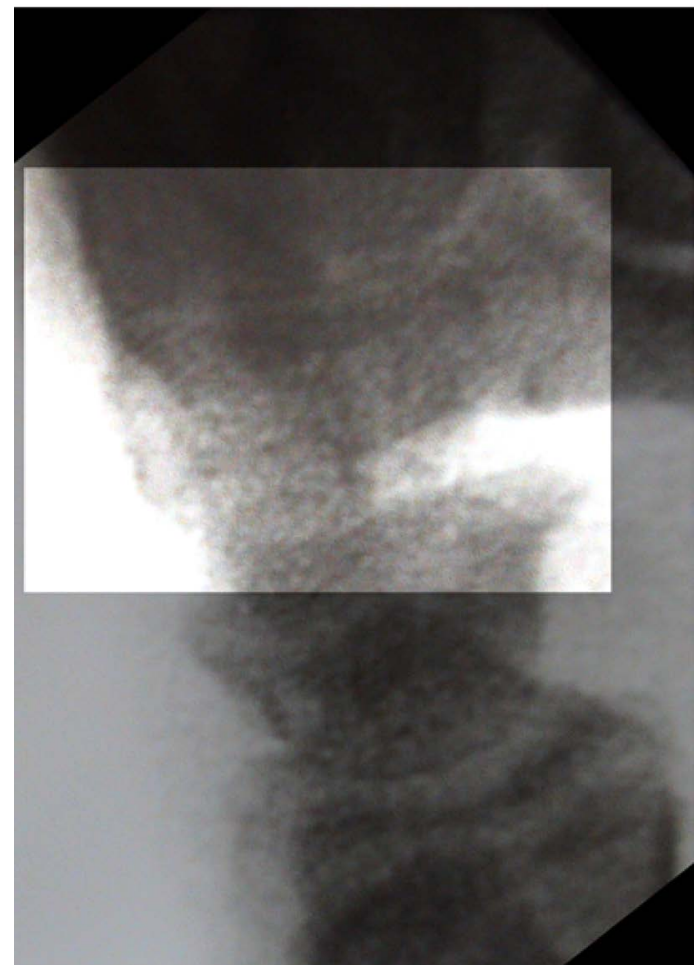

Figure 10. Radiographic appearances at a year showing preservation of the interposition and no loss of carpal angles. 
were capitohamate, 1 scapholunate and 1 trapeziocapitate. All were incidental findings and the patients denied previous injury, infection or wrist dysfunction. It was concluded that unlike tarsal coalitions, carpal coalitions were all asymptomatic, incidental findings which did not lead to wrist dysfunction.

A whole spectrum of synchondrosis exists ranging from partial to complete fusion, depending on the degree of formation of the articular cartilaginous elements [18].

In 1952, de Villiers Minaar [8] published a classification of lunate-triquetral coalition from a series of 12 cases based on the degree of fusion and associated anomalies. Type 1 is a proximal pseudoarthrosis of the lunotriquetral junction. Type 2 is a proximal osseous bridge with a distal notch. Type 3 is a complete fusion. Type 4 is a fusion with associated anomalies. The Minaar classification is useful for classifying coalitions between other carpal bones.

Of the four types of coalition, it appears that only Type 1 is likely to become symptomatic [2]. This may be as a result of the cartilaginous destruction that occurs secondary to intercarpal motion at the pseudoarthrosis. Type 1, with movement across an incomplete synostosis can cause degeneration of abnormally thin cartilage and therefore painful arthritis [12]. Types 2 - 4 allow no motion and therefore tend to be symptomatic when associated with a fracture [6]. An incomplete coalition resembling a pseudoarthrosis (Type 1 coalition) is not easily diagnosed and is likely to be missed by plain radiographic examination [21]. Multiple projections [12] are often required and care must be taken not to confuse true congenital coalitions with fusions secondary to acquired disease [14].

In Delaney's series [1], of the 32 lunotriquetral coalitions, 1 was Minaar type 1, 20 were Minaar type 2 and 11 were Minaar type 3. These results and other reports [22] show that the coalition may not always be complete. Abnormal differentiation in the interzone may allow cartilaginous continuity to occur without intervening synovial tissue producing incomplete coalition [2].

Isolated lunato-triquetral coalition is the most common, followed by capitate-hamate, pisiform-triquetral and trapezium-trapezoid [17] [18] [19] [21]. Isolated coalitions usually involve the same carpal row, while syndrome related coalitions often affect bones in different rows with more than two carpal bones affected [3] [10] [18] [23]. Coalitions are associated with other congenital anomalies and hereditary syndromes [14] [17] [19] such as arthrogryposis, synphalangea, diastrophic dwarfism, Turner's syndrome, Ellis-van Creveld syndrome. An association with foetal alcohol syndrome is also documented [24].

Isolated coalitions of the scaphoid with trapezium and trapezoid (ST/STT) in otherwise healthy individuals are rare. Unlike other isolated coalitions in the literature these involve bones in both the proximal and distal carpal rows, though they can be considered to be in the lateral column of the wrist. STT coalitions have been associated with bilateral lunate-triquetral coalition [25], hand-footuterus syndrome [26], otopalatadigital syndrome [27] and hereditary symphalangism [28]. 
There are only five reports in the literature that appear to be isolated nonsyndromic STT coalitions [10] [11] [17] [19] [29]. Barnes et al. in 1992 reported a case of an incidental finding of bilateral ST coalitions in a 38 year old black male who was being treated for carpometacarpal dislocations following a road traffic accident. He had no other coalitions or significant medical history. Interestingly on investigation, his twin brother was also found to have bilateral ST coalitions and was asymptomatic as well. Ingram et al. in 1997 reported an STT coalition as an incidental finding whilst investigating a fifth metacarpal fracture in a young black male. The wrist was totally asymptomatic and the patient denied any previous injury, illness or medical conditions. Smith-Hoefer et al. in 1985 reported on a 15 year old black male with a nine year history of intermittent bilateral wrist pain precipitated by activity and relieved by rest with decreased range of movement. Radiological investigations revealed bilateral scapho-trapezial synchondrosis. The patient had no other associated congenital abnormalities or rheumatological conditions. Kaneko et al. in 2000 reported a 30 year old Asian female with a 10 year history of wrist pain, exacerbated after commencing work at a factory. The symptoms mimicked those of de Quervains tenosynovitis; however investigations revealed a ST coalition which corresponded to the site of maximum symptoms. Weinzweig et al. in 1997 reported 2 cases. A 19 year old male who had wrist pain and stiffness had an STT synchondrosis found on surgical exploration. He did also have a fibrous scaphoid non union which may have been the cause of his pain. The second case was a 17 year old girl with a 10 year history of wrist pain, worsening after a hyperextension injury. Investigation and surgery confirmed a STT coalition.

The five cases presenting to our unit were isolated, nonsyndromic coalitions. The patients were otherwise healthy individuals who presented with wrist pain after suffering minor trauma to the affected wrist. Radiographs showed the coalition (Figure 1, Figure 5) and this was confirmed on CT scan (Figure 2, Figure 6) to exclude any other pathology. One patient was noted to have bilateral radiographic evidence of a coalition, though he was symptomatic on the limb previously affected by trauma. It has already been mentioned that the abnormal joints formed by the coalition are predisposed to become symptomatic after injury due to the altered configuration of the articulation and may account for the patient only experiencing symptoms on one side.

Five failed to respond to six months of conservative management and underwent operative management. These patients had resection of the coalition (all STT), with limited resection of the distal scaphoid. Distal scaphoid resection has been described [30] for the treatment of symptomatic STT arthritis and was thought by the authors to be a sensible way of improving symptoms in these patients, not only helping to preserve range of motion and function but also pain. All had a capsular interposition graft.

\section{Summary}

Isolated STT coalition is rare and generally asymptomatic. However, the coali- 
tions may predispose or lead to symptomatic pathology following trauma or excessive load to the affected wrist. Most cases can be treated conservatively but persistent symptoms may require operative intervention. Limited resection of the distal scaphoid with excision of the coalition may be another treatment option when symptoms fail to settle with non-operative treatment.

\section{References}

[1] Delaney, T.J. and Eswar, S. (1992) Carpal Coalitions. The Journal of Hand Surgery (Am), 17, 28-31. https://doi.org/10.1016/0363-5023(92)90108-2

[2] Simmons, B.P. and McKenzie, W.D. (1985) Symptomatic Carpal Coalition. The Journal of Hand Surgery (Am), 10, 190-193. https://doi.org/10.1016/S0363-5023(85)80103-9

[3] Knezevich, S. and Gottesman, M. (1990) Symptomatic Scapholunatotriquetral Carpal Coalition with Fusion of the Capitometacarpal Joint. Clinical Orthopaedics and Related Research, No. 251, 153-154.

[4] van Schoonhoven, J., Prommersberger, K.J. and Schmitt, R. (2001) Traumatic Disruption of a Fibrocartilage Lunate-Triquetral Coalition-A Case Report and Review of the Literature. Hand Surgery, 6, 103. https://doi.org/10.1142/S0218810401000497

[5] Peyton, R.S. and Moore, J.R. (1994) Fracture through a Congenital Carpal Coalition. The Journal of Hand Surgery $(A m), 19,369-371$.

https://doi.org/10.1016/0363-5023(94)90047-7

[6] Ganos, D.L. and Imbriglia, J.E. (1991) Symptomatic Congenital Coalition of the Pisiform and Hamate. The Journal of Hand Surgery (Am), 16, 646-650.

https://doi.org/10.1016/0363-5023(91)90188-H

[7] Stabler, A., Glaser, C., Reiser, M. and Resnick, D. (1999) Symptomatic Fibrous Lunato-Triquetral Coalition. European Radiology, 9, 1643-1646.

[8] De Villiers Minaar, A.B. (1952) Congenital Fusion between the Lunate and Triquetral Bones in the South African Bantu. The Journal of Bone and Joint Surgery, 34B, 45-48.

[9] Ritt, M., Maas, M. and Bos, K. (2001) Minnaar Type 1 Symptomatic Lunotriquetral Coalition: A Report of Nine Patients. The Journal of Hand Surgery, 26, 261-270.

[10] Smith-Hoefer, E. and Szabo, R.M. (1985) Isolated Carpal Synchondrosis of the Scaphoid and Trapezium. The Journal of Bone \& Joint Surgery, 67, 318-320. https://doi.org/10.2106/00004623-198567020-00020

[11] Kaneko, K., Matsumura, K. and Maruyama, Y. (2000) Congenital Synostosis between the Scaphoid and the Trapezium as a Cause of Tenosynovitis Simulating de Quervain's Disease. Chirurgie de la Main, 19, 187-190.

[12] Richterman, I. and Scott, K. (1996) Symptomatic Pisiform Hamate Synchondrosis: A Case Report and Review of the Literature. The Journal of Hand Surgery, 21, 311-313. https://doi.org/10.1016/S0363-5023(96)80129-8

[13] Gottschalk, M.B., Danilevich, M. and Gottschalk, H.P. (2016) Carpal Coalitions and Metacarpal Synostoses: A Review. Hand, 11, 271-277. https://doi.org/10.1177/1558944715614860

[14] Cope, J.R. (1974) Carpal Coalition. Clinical Radiology, 25, 261-266. https://doi.org/10.1016/S0009-9260(74)80068-1

[15] Wagner, C.J. (1950) Methods of Treatment of Bennett's Fracture Dislocation. American Journal of Surgery, 80, 230-231. https://doi.org/10.1016/0002-9610(50)90537-X 
[16] Green, D.P. and O'Brien, E.T. (1978) Open Reduction of Carpal Dislocations: Indications and Operative Techniques. The Journal of Hand Surgery, 3, 250-265. https://doi.org/10.1016/S0363-5023(78)80089-6

[17] Ingram, C., Hall, R.F. and Gonzalez, M. (1997) Congenital Fusion of the Scaphoid, Trapezium, Trapezoid and Capitate. Journal of Hand Surgery (European Volume), 22, 167-168. https://doi.org/10.1016/S0266-7681(97)80053-8

[18] Weinzweig, J., Watson, H.K., Herbert, T.J. and Shaer, J.A. (1997) Congenital Synchondrosis of the Scaphotrapezio-Trapezoidal Joint. The Journal of Hand Surgery (Am), 22, 74-77. https://doi.org/10.1016/S0363-5023(05)80182-0

[19] O’Rahilly, R. (1953) A Survey of Carpal and Tarsal Anomalies. The Journal of Bone \& Joint Surgery, 35, 626-642. https://doi.org/10.2106/00004623-195335030-00010

[20] Cockshott, W.P. (1969) Pisiform Hamate Fusion. The Journal of Bone \& Joint Surgery, 51, 778-780. https://doi.org/10.2106/00004623-196951040-00019

[21] Sferopoulos, N. and Tsitouridis, I. (2003) Carpal Coalition: A Rare Coincidence with Hand Deficiencies. Acta Orthopaedica Belgica, 69, 317-320.

[22] Resnick, C.S., Grizzard, J.D., Simmons, B.P. and Yaghmai, I. (1986) Incomplete Carpal Coalition. American Journal of Roentgenology, 147, 301-304.

[23] Orlin, H. and Alpert, M. (1967) Carpal Coalition in Arthrogryposis Multiplex Congenita. The British Journal of Radiology, 40, 220-222.

https://doi.org/10.1259/0007-1285-40-471-220

[24] Jaffer, Z., Nelson, M. and Beighton, P. (1981) Bone Fusion in Foetal Alcohol Syndrome. The Journal of Bone and Joint Surgery, 63B, 569-571.

[25] Zielinski, C.J. and Gunther, S.F. (1981) Congenital Fusion of the Scaphoid and Trapezium. The Journal of Hand Surgery $(A m), 6,220-222$.

https://doi.org/10.1016/S0363-5023(81)80073-1

[26] Pozanski, A.K., Stern, A.M. and Gall, J.C. (1970) Radiographic Findings in HandFoot-Uterus Syndrome (HFUS). Radiology, 95, 129-134.

[27] Gall, J., Stern, A.M., Pozanski, A.K., Garn, S.M., Weinstein, E.D. and Hayward, J.R. (1972) Oto-Palato-Digital Syndrome: Comparison of Clinical and Radiographic Manifestations in Males and Females. The American Journal of Human Genetics, 24, 24-36.

[28] Harle, T.S. and Stevenson, J. (1967) Hereditary Symphalangism Associated with Carpal and Tarsal Fusions. Radiology, 89, 91-94. https://doi.org/10.1148/89.1.91

[29] Barnes, C.L., Frazier, G.T. and Hixson, M.L. (1992) Bilateral Congenital Fusion of the Scaphoid and Trapezium in Identical Twins. Orthopedics, 15, 739-741.

[30] Garcia-Elias, M., Lluch, A.L., Farreres, A., Castillo, F. and Saffar, P. (1999) Resection of the Distal Scaphoid for Scaphotrapeziotrapezoid Osteoarthritis. Journal of Hand Surgery (European Volume), 24, 448-452.

https://doi.org/10.1054/jhsb.1999.0169 
Submit or recommend next manuscript to SCIRP and we will provide best service for you:

Accepting pre-submission inquiries through Email, Facebook, LinkedIn, Twitter, etc. A wide selection of journals (inclusive of 9 subjects, more than 200 journals)

Providing 24-hour high-quality service

User-friendly online submission system

Fair and swift peer-review system

Efficient typesetting and proofreading procedure

Display of the result of downloads and visits, as well as the number of cited articles Maximum dissemination of your research work

Submit your manuscript at: http://papersubmission.scirp.org/

Or contact ojo@scirp.org 